\title{
Research on Customer Demand for Electricity in Electricity Market Environment: Based on Henan Province
}

\author{
Shuo Yin ${ }^{1,2, ~}$, Meng Yang ${ }^{1,2}$, Hongkun Bai ${ }^{1,2}$, Dawei Song ${ }^{1,2}$, Hujun Li ${ }^{1,2}$, Qinchen Yang ${ }^{1,2}$ \\ ${ }^{1}$ State Grid Henan Economic Research Institute, No.87 Songshan Road, Zhengzhou, China \\ ${ }^{2}$ Henan Energy Development Research Institute, No.87 Songshan Road, Zhengzhou, China \\ *Corresponding author: tel: 13137132263,Email: 411761498@qq.com
}

Keywords: energy economy; econometric analysis; electricity consumption

\begin{abstract}
Electricity consumption prediction is of great importance to the economic and social development and the balance of supply and demand of the power system. Influenced by the economic situation, the growth rate of the expansion of regional industry is showing the trend of volatility. It not only affects the power consumption of the region, but also affects the safety of power grid dispatching and operation. In order to better grasp the trend of regional power demand, the economic and social development of the service area and the safe and smooth operation of the power grid, in this paper, based on the mining of incremental big data of regional industry expansion, with simulation analysis econometrics ARMA, DID, etc, at the beginning of the construction of the power demand forecasting model, based on the support of large-scale expansion of industry data, according to the industry research industry, the situation of capacity expansion, load utilization and electricity demand, and the case of Henan Province, the regional electricity consumption is predicted.
\end{abstract}

\section{Cleansing of Electricity Data}

In recent years, influenced by the economic situation, regional industry reporting for expanding capacity growth trend volatility, it is not only a certain effects on the regional power consumption, but also affect the safety of power grid dispatch and operation.

Based on the business expanding worksheet in the marketing system, the data of 52 industries and enterprises in Henan Province from January 2014 to June 2017 were cleaned. In the process of data cleaning, focus on removing industry expansion information which non-production electricity need to apply for. After cleaning, the data of business expanding should be reflected in the user's power data after the installation is complete. To ensure that the use of industry expansion data reflected in the electricity bill after the user to complete the installation. The key excluded data include: the business expanding data of application for change of power supply line, the business expanding data of application for dual circuit power access, the business expanding data which repeat the application for a short time. 


\section{Model setting}

Changes in electricity consumption after the expansion of the industry will be affected by a series of external factors such as economy, climate and holidays. On the base of fully consider all the external facotors, ARMA non-expansion model will be used to predict the comprehensive nature growth rate of Henan province electricity industry.

ARMA (p, q) Non-deployment expansion forecast model is autoregressive moving average model, where AR is autoregressive, $\mathrm{p}$ is autoregressive; MA is moving average and $\mathrm{q}$ is moving average. The basic idea of ARMA non-expansion forecasting model is that the data sequence formed by non-deployment expansion over time is regarded as a random sequence, and the mathematic model is used to describe the non-expansion sequence. The future value of nonexpansion can be predicted from the past and present value of non-expansion.

Henan ARMA non-expansion expansion forecast model is as follows:

$$
Y_{t}=\theta+\alpha_{1} Y_{t-1}+\beta_{0} \mu_{t}+\beta_{1} \mu_{t-1}
$$

Where is a constant different from that of a random error term with zero mean and constant variance. In ARMA non-expansion model, $t=30, p=1$ and $q=1$, that is, there are 1 autoregressive term and 1 moving average term, which is the ARMA $(1,1)$ process. According to the ARMA model, the non-expansion capacity and expansion rate of expansion in $t+1$ phase can be predicted by rolling.

\section{The Forecast of Power Consumption in Henan Province}

\subsection{The estimate of sub-sector business expanding period electricity}

After the Business expanding occurred, it needs to experience some of the power cycle, in order to fully reflect the electricity consumption. Consider the expansion of Henan Province, installed capacity within 12 months after the installation of new capacity and permanent capacity reduction account sales situation. According to the business expanding report installments, power transmission time, respectively, from the user meter to obtain the power of the next 12 months, the expansion of the installation of business expanding month set as the base month ( 0 months), after the monthly electricity is set to 1-12 month. Different industries due to different industrial characteristics, the power cycle is also different, through the expansion of the load after the installation load ratio tends to be stable in the month and the reference month of the difference between the cycle as the power cycle, through the energy economy break-point regression method to determine the structural changes in the load factor and tends to be stable node month.

Assume that there are $\mathrm{n}$ months before the month of the node month, and m months after the node month. Among them: $\mathrm{n}=12$ - $\mathrm{m}$

Breakpoint back to the core idea is: if there is no structural change in the model, the nodes in $n$ months before the sequence of $\mathrm{m}$ a month after the month of sum of squared residuals and node sequence of sum of squared residuals on the statistics should not be significantly different, so the original hypothesis H0 regression equation for the two samples is not significantly different in statistics, namely there is no structural change. On this basis, the use of the $\mathrm{F}$ test to test data obtained by the first $\mathrm{n}$ rate on the parameters and the parameters of the data obtained by m months after load rate are equal, thus determine whether structure changed, check formula is as follows:

$$
F=\frac{\left(R S S_{R}-R S S_{U R}\right) / k}{R S S_{U R} /(n+m-2 k)}
$$


Whether the rate of load is stable in the month of the node is measured by $\mathrm{F}$ value. The electrografting cycle of 52 industrial sequences in henan province is shown in table 1.

\subsection{The calculation of load change rate of business expanding}

Due to the different characteristics of the industry, the changing load factor of various industries in Henan is not consistent. From the perspective of industry segmentation, this paper calculates the load rate of business expanding in each industry according to the reporting for expanding capacity of all users in the 52 industries.

$$
L R\left(I N D, M O N, T Y P_{j}\right)=\frac{\sum_{i=1}^{s} E_{i}}{\sum_{i=1}^{s} A_{i} \times 24 \times 30}
$$

Among them, LR is the load change rate of reporting for expanding capacity, IND is an industry type; MON represents the industry's receiving cycle; TYP represents the type of expansion application; $j=1$ is newly installed, increase capacity, $j=0$ is canceling the account, volume reduction; $\mathrm{E}$ is the increase / decrease value of user's monthly electricity consumption, $\mathrm{i}$ is the $\mathrm{i}$ 's user of the industry, A is the increased / reduced capacity of users' applications (TYP is a positive at 1 , TYP is a negative at 0 ).

\subsection{The forecasting of business expanding electricity demand}

First Forecast electricity of Sub-industry business expanding:

$$
\mathrm{LEi}=\mathrm{LRi} \times \mathrm{Ai}
$$

Among them, LEi is i's electricity of industry business expanding, $i=1,2 \ldots$. S, LRi is i's change of load rate of industry business expanding, Ai is the industry expansion of statistical capacity.

Second Forecast electricity of industry business expanding:

$$
A L E=\sum_{i=1}^{s} L E i
$$

Among them, the ALE is the electricity of whole industry business expanding. It was estimated that in July 2017, the electricity of business expanding in Henan province will be 1.48 million $\mathrm{KWH}$, and the impact electricity of the business expanding in July and December 2017 will be 12.73 billion KWH.

\subsection{Prediction results}

Household electricity consumption in Henan Province alone forecast, as the business expanding has a small impact on residents of electricity, the analysis of the impact of business expanding on the electricity consumption will be a single column of residential electricity. The use of electricity by residents is based on the monthly electricity consumption of historical residents and the natural rate of growth. Among them, the part of the natural growth rate is still predicted by the ARMA model. According to ARMA (1, 1) model prediction results, in July 2017, Henan province's residents use 3.95 billion KWH of electricity. The year-on-year growth rate was 7\%. 
Table 1 Load change rate of 52 industries in Henan

\begin{tabular}{|c|c|c|c|}
\hline Industry & $\begin{array}{c}\text { Load rate } \\
\text { changes }\end{array}$ & Industry & $\begin{array}{c}\text { Load rate } \\
\text { changes }\end{array}$ \\
\hline 01, Citizens & $0.40 \%$ & $\begin{array}{l}\text { 27, Ferrous metal smelting and rolling } \\
\text { processing industry }\end{array}$ & $1.72 \%$ \\
\hline 02, Village resident & $0.61 \%$ & $\begin{array}{l}\text { 28, Non-ferrous metal smelting and rolling } \\
\text { processing industry }\end{array}$ & $3.82 \%$ \\
\hline 03, Agriculture & $0.73 \%$ & 29, Metal products industry & $0.16 \%$ \\
\hline 04, Forestry & $-1.18 \%$ & $\begin{array}{c}\text { 30, General and special equipment } \\
\text { manufacturing }\end{array}$ & $1.58 \%$ \\
\hline 05, Animal husbandry & $1.06 \%$ & $\begin{array}{c}\text { 31, Transportation,Electrical,Electronic } \\
\text { Equipment Manufacturing }\end{array}$ & $1.02 \%$ \\
\hline 06, Fisheries & $0.59 \%$ & 32, Crafts and other manufacturing (light) & $-0.86 \%$ \\
\hline $\begin{array}{l}\text { 07, Agriculture,forestry,animal } \\
\text { husbandry,fishery services }\end{array}$ & $-0.02 \%$ & $\begin{array}{l}\text { 33, Abandoned resources and waste materials } \\
\text { recycling processing industry }\end{array}$ & $-2.58 \%$ \\
\hline 08 , Coal mining and washing industry & $-1.08 \%$ & $\begin{array}{c}\text { 34, Electricity,heat production and supply } \\
\text { industry }\end{array}$ & $-1.12 \%$ \\
\hline 09, Oil and gas mining industry & $1.59 \%$ & 35, Gas production and supply & $3.31 \%$ \\
\hline 10, Black metal mining industry & $-1.78 \%$ & 36, Water production and supply & $-0.08 \%$ \\
\hline 11, Non-ferrous metal mining industry & $3.36 \%$ & 37, Construction industry & $0.66 \%$ \\
\hline 12, Non-metallic mining industry & $4.47 \%$ & 38, Transportation industry & $1.09 \%$ \\
\hline 13, Other mining industry & $-1.23 \%$ & 39, Warehousing & $0.64 \%$ \\
\hline $\begin{array}{l}\text { 14, Food,Beverage and Tobacco } \\
\text { Manufacturing (light) }\end{array}$ & $2.92 \%$ & 40, Post industry & $1.66 \%$ \\
\hline 15, Textile industry (light) & $2.93 \%$ & $\begin{array}{l}\text { 41, Telecommunications and other information } \\
\text { transmission services }\end{array}$ & $1.60 \%$ \\
\hline $\begin{array}{l}\text { 16, Clothing shoes and hats,leather } \\
\text { down and its products industry (light) }\end{array}$ & $-0.48 \%$ & 42, Computer Services and Software Industry & $0.10 \%$ \\
\hline $\begin{array}{l}\text { 17, Wood processing and products and } \\
\text { furniture manufacturing }\end{array}$ & $4.98 \%$ & 43, Wholesale and retail trade & $1.87 \%$ \\
\hline $\begin{array}{l}\text { 18, Paper and paper products industry } \\
\text { (light) }\end{array}$ & $2.53 \%$ & 44, Accommodation and catering industry & $1.35 \%$ \\
\hline $\begin{array}{l}\text { 19, Printing and recording media } \\
\text { replication (light) }\end{array}$ & $1.23 \%$ & 45, Financial industry & $2.01 \%$ \\
\hline 20, Style supplies manufacturing (light) & $-0.69 \%$ & 46, Real estate & $0.97 \%$ \\
\hline $\begin{array}{c}\text { 21, Petroleum Processing,Coking and } \\
\text { Nuclear Fuel Processing }\end{array}$ & $-0.92 \%$ & $\begin{array}{c}\text { 47, Leasing and business services,residential } \\
\text { services and other services }\end{array}$ & $0.81 \%$ \\
\hline $\begin{array}{l}\text { 22, Chemical raw materials and } \\
\text { chemical products manufacturing }\end{array}$ & $5.50 \%$ & $\begin{array}{c}\text { 48, Scientific Research,Technical Services and } \\
\text { Geological Prospecting }\end{array}$ & $0.18 \%$ \\
\hline $\begin{array}{l}\text { 23, Pharmaceutical Manufacturing } \\
\text { (light) }\end{array}$ & $7.39 \%$ & $\begin{array}{l}\text { 49, Water conservancy,environment and public } \\
\text { facilities management } \\
\end{array}$ & $0.43 \%$ \\
\hline 24, Chemical fiber manufacturing (light) & $3.82 \%$ & 50, Education,Culture,Sports and Entertainment & $0.57 \%$ \\
\hline 25, Rubber and plastic products industry & $3.16 \%$ & 51, Health,Social Security and Social Welfare & $1.19 \%$ \\
\hline $\begin{array}{l}\text { 26, Non-metallic mineral products } \\
\text { industry }\end{array}$ & $1.02 \%$ & $\begin{array}{l}\text { 52, Public administration and social } \\
\text { organizations,international organizations }\end{array}$ & $0.93 \%$ \\
\hline
\end{tabular}


According to the general formula of the business expanding-electricity conduction prediction:

Total electricity consumption in Henan Province $=$ residential electricity consumption + the whole industry expansion affects power + non-industry expansion affects power. The total energy consumption of the whole society in 2017 was about 316 billion 500 million kwh, with a year-onyear growth rate of $6.2 \%$.

\section{Conclusion}

Using ARMA, DID and other energy econometric simulation analysis methods. At the beginning of the construction of the power demand forecasting model based on the big data supported by the business expanding. Sub-industry research business expanding relationship between the cases, the operating capacity, load utilization and demand for electricity. Taking Henan province as an example, the regional electricity consumption is predicted. With Henan as an empirical calculation, the total electricity consumption in Henan province was about 316 billion 500 million kwh in 2017, and the growth rate was $6.2 \%$ over the same period, The actual error with the year was $0.19 \%$.

\section{Acknowledgments}

This work was financially supported by State grid Science and technology project fund (Research on the electricity market maturity evaluation technology and differentiated operation model of power Grid Company under the new round of electric system reform.5217L017000M).

\section{References}

[1] Song Xiaohua, Zu Pie, Yi Jing, Liu Da. An optimally combined forecast model for long-term power demand based on improved grey and SVM model[J], Journal of Central South University (Science and Technology),2012.

[2] Sun Zhi. An expert system algorithm for short-term electric quantity prediction using software [J], Power Demand Side Management, 2004.

[3] Zhang Yu jing, Zhi Qun, Wang Xiao yu, Wang Fang. The Innovative Application of Large Data Platform to Resource Integration and Savings for Power Industry Expansion and Power Generation Plan Compilation [J], Resources Economization \& Environmental Protection, 2016.

[4] Hui Chen, Zheng, An gang, Zou Heping, Zhang Mi. District Electric Power Comsumption Prediction and Management Simulation [J] Computer Simulation, 2016.

[5] Yan Wei, Cheng Chao, Xue Bin, Li Dan, Chen Fei. Forecasting for Monthly Electricity Consumption Using X12 Multiplication Method and ARIMA Model [J], Proceedings of the CSU-EPSA, 2016.

[6] Cao Ming. Dynamic Analysis and Forecast of Energy Economic Efficiency of China [J], China Population Resources and Environment, 2011.

[7] Li Xiang. Medium and Long-term Electricity Demand Forecasting Method Based on Industry Classification [D], South China University of Technology, 2016.

[8] Zhang Qiang, Wang Yi, LI Dingrui, Zhu Wenjun. Monthly Electricity Forecast Based on X-12-ARIMA Seasonal Decomposition and Annual Electricity Correction [J], Electric Power Construction, 2017. 